\title{
Method for discovering novel DNA viruses in blood using viral particle selection and shotgun sequencing
}

\author{
Mya Breitbart and Forest Rohwer \\ BioTechniques 39:729-736 (November 2005) \\ doi $10.2144 / 000112019$
}

\begin{abstract}
Rapid identification of viruses is needed to monitor the blood supply for emerging threats. Here we present a method that meets these criteria and allows for the shotgun sequencing of novel, uncultured DNA viruses directly from human blood. This method employs selection based on the physical properties of viruses combined with sequence-independent amplification and cloning. We show that both single-and double-stranded DNA viruses can be recovered from blood samples using this approach. In addition, we report the discovery of novel anellovirus sequences in the blood of healthy donors. PCR primers designed to amplify these novel anellovirus sequences were then used to verify the presence of these viruses in the general donor population.
\end{abstract}

\section{INTRODUCTION}

New viral infections in humans may be emerging at an increasing rate (1). The safety of the blood supply is currently maintained by selective screening of donors (2), pathogen reduction (3), and nucleic acid and antibody testing for known viruses, including human immunodeficiency virus (HIV), hepatitis B virus (HBV), hepatitis $\mathrm{C}$ virus (HCV), human T cell lymphotrophic virus (HTLV), and West Nile virus (WNV). These practices have made the blood supply extremely safe from the transmission of known viruses (the risk of contracting HIV or HCV through a blood transfusion is less than 1 in 2,000,000) (4).

The largest potential threats to the blood supply are posed by novel pathogens, which would escape current screening techniques. In order to identify emerging viruses, an active surveillance system capable of continually monitoring the blood supply is needed. Hybridization to DNA microarrays containing all known viral sequences and low-stringency PCR using degenerate primers to highly conserved viral sequences have successfully been used to identify and characterize novel viruses $(5,6)$. These methods rely on conserved sequences being present within viral genomes, which makes them inadequate for the discovery of completely novel viral types in human blood samples.

The use of representative differential amplification (RDA) (7) has led to the discovery of several novel viruses in humans, including HCV (8), hepatitis GB virus (9), herpesvirus 8 (10), and Torque teno virus (TTV) (11). RDA was originally intended for comparing two cellular genomes, and applying this method to viral discovery in human blood requires that the composition of the background host DNA to be subtracted out is similar in both the tester and driver samples. In addition, RDA typically involves large quantities of DNA, which would require a high level of viremia before the virus could be recovered. While RDA is appropriate if samples from the same individual are being compared before and after viral infection, it is not clear that this approach will be applicable to blood pooled from multiple individuals.

Two recent studies have presented viral discovery methods that utilize selection for viral particles (based on size, density, and nuclease resistance), followed by sequence-independent amplification $(12,13)$. These approaches have been used to identify new bovine parvoviruses present in commercial bovine serum (12), sequence novel viruses from the plasma of patients with symptoms of acute viral infection (14), and diagnose herpes simplex virus type 1 (HSV-1) in the supernatant of infected cells isolated from the mouthwashing material of a chronic fatigue syndrome patient (13).

Several viruses, such as TTV (1517), TTV-like mini virus (TLMV) (18), 


Protocol 1. Overview of the Methodology for Obtaining Purified Viral DNA from
Whole Blood Samples
\begin{tabular}{|rl|}
\hline 1. & Removal of blood cells by centrifugation \\
2. & Purification of viral particles by $\mathrm{CsCl}$ density-dependent centrifugation \\
(results may be visualized by electron microscopy; see Figure 1) \\
3. & Chloroform treatment \\
4. & DNase I incubation \\
5. & Concentration and desalting \\
6. & DNA extraction \\
7. & PCR for quality control (see Figure 2) \\
8. & Sequence-independent amplification \\
9. & DNA shearing \\
10. & Linker-addition and PCR amplification of fragments \\
11. & Cloning and sequencing \\
12. & Bioinformatic analyses \\
13. & Confirmation by specific PCR (see Figure 3) \\
\hline
\end{tabular}

SEN virus (SENV) (19), Epstein-Barr virus (20), and B19 (21) are found in the blood of healthy people. The process of discovering novel blood viruses is hindered by methodological limitations such as low viral DNA content, abundance of host and mitochondrial DNA, and the absence of genes that are conserved among all viruses. Here we present a method to shotgun-sequence novel, uncultured DNA viruses directly from human blood. This method employs selection based on the physical properties of viruses combined with sequence-independent amplification and cloning. Using this method, we discovered novel anellovirus sequences in the blood of healthy donors.

\section{MATERIALS AND METHODS}

\section{Blood Collection}

All blood collection was performed by technicians at the General Clinical Research Center at the Scripps Research Institute (San Diego, CA, USA). Ten milliliters of blood were collected from healthy blood donors into sodium heparin vacutainers (BD Biosciences, Franklin Lakes, NJ, USA) and stored at $4{ }^{\circ} \mathrm{C}$ until processing (within 1 week).

\section{Sample Descriptions}

Library 1 was constructed from blood pooled from 20 healthy donors collected in November 2004. Libraries 2 and 3 were constructed from blood pooled from 15 healthy donors collected in February 2005. The pooled plasma samples for Libraries 1 and 2 were spiked with $10^{7}$ bacteriophage M13 particles per milliliter as a tracer to ensure the recovery of single-stranded DNA (ssDNA) viruses. Library 3 was not spiked with any tracers. For screening with specific primers, plasma was pooled from approximately 100 additional healthy donors (collected between September 2004 and February 2005).

\section{Isolation of Viral DNA}

The methods for obtaining viral DNA from blood samples are outlined in Protocol 1. Whole blood samples were centrifuged at $3000 \times g$ at $4^{\circ} \mathrm{C}$ for 10 min to pellet the blood cells. Eight and a half milliliters of cell-free plasma were loaded onto a cesium chloride $(\mathrm{CsCl})$ step gradient consisting of 1 $\mathrm{mL}$ each of $1.7,1.5$, and $1.2 \mathrm{~g} / \mathrm{mL}$ in $1 \times$ phosphate-buffered saline $(1 \times \mathrm{PBS}$; $137 \mathrm{mM} \mathrm{NaCl}, 2.7 \mathrm{mM} \mathrm{KCl}, 4.3 \mathrm{mM}$ $\mathrm{Na}_{2} \mathrm{HPO}_{4}, 1.4 \mathrm{mM} \mathrm{KH} \mathrm{PO}_{4}, \mathrm{pH} 7.3$ ). The gradient was designed to capture all known groups of DNA viruses (22). The gradients were ultracentrifuged at $55,000 \times g$ at $4^{\circ} \mathrm{C}$ for $2 \mathrm{~h}$, and the $1.2-1.5 \mathrm{~g} / \mathrm{mL}$ fraction was collected. This fraction was stained with $\mathrm{SYBR}^{\circledR}$ Gold (Molecular Probes, Eugene, OR, USA) and viewed under epifluorescence and electron microscopy to ensure that it contained virus-like particles $(23,24)$. The $\mathrm{CsCl}$-purified viral particles were then incubated with 0.2 volumes of chloroform for $10 \mathrm{~min}$ at room temperature. The chloroform was pelleted, and the supernatant was removed and incubated with $2.5 \mathrm{U}$ DNase I (Sigma-Aldrich, St. Louis, MO, USA) per microliter of sample for $2 \mathrm{~h}$ at $37^{\circ} \mathrm{C}$. This sample was then concentrated and washed twice with $1 \times$ PBS on a Microcon ${ }^{\circledR} 30$ (Millipore, Billerica, MA, USA). EDTA was added to a final concentration of $20 \mathrm{mM}$ to inactivate the DNase I, and DNA was then extracted using the QIAamp ${ }^{\circledR}$ MinElute $^{\text {TM }}$ Virus Spin Kit (Qiagen, Valencia, CA, USA) according to the manufacturer's instructions. Total DNA was also extracted from unprocessed cell-free plasma from the healthy donors using the QIAamp Blood Mini Kit (Qiagen). This was used for the comparison of human, mitochondrial, and TTV DNA found in unprocessed plasma versus viral DNA purified using the method outlined in Protocol 1.

\section{PCR to Check DNA Quality}

Viral DNA extracted from the blood samples was screened by PCR for the presence of $(i)$ human 18S rDNA, (ii) human mitochondrial DNA, and (iii) TTV. All primer sequences are listed in Table 1. PCR products positive for TTV in the nested reaction were sequenced for verification. The PCR mixture (50 $\mu \mathrm{L}$ total volume) for the specific primer

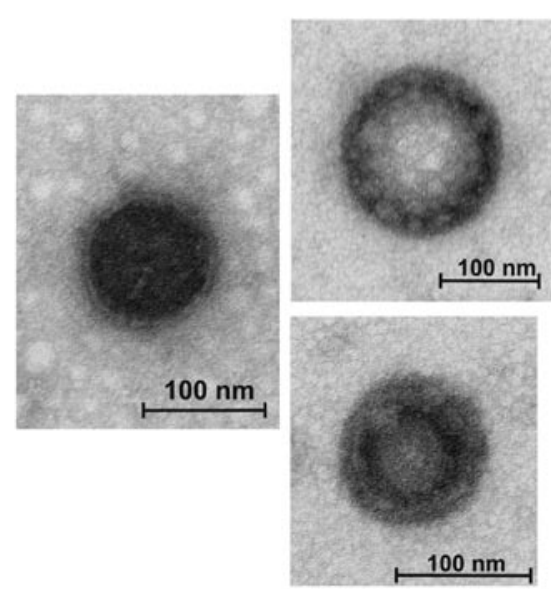

Figure 1. Transmission electron micrographs of some viruses found in the blood of healthy donors. 
sets contained $5 \mu \mathrm{L}$ of target DNA, 1× FideliTaq $^{\mathrm{TM}}$ PCR Master Mix (USB, Cleveland, OH, USA), and $1 \mu \mathrm{M}$ each primer. The thermal cycler conditions were $5 \mathrm{~min}$ at $94^{\circ} \mathrm{C} ; 35$ cycles of $1 \mathrm{~min}$ at $94^{\circ} \mathrm{C}, 1 \mathrm{~min}$ at $55^{\circ} \mathrm{C}$, and $1 \mathrm{~min}$ at $72^{\circ} \mathrm{C}$; and $10 \mathrm{~min}$ at $72^{\circ} \mathrm{C}$.

\section{Electron Microscopy}

The CsCl-purified viral particles were adsorbed to glow-discharged formvar-coated 200-mesh copper grids for $5 \mathrm{~min}$. The grids were then stained in $1 \%$ uranyl acetate for $20 \mathrm{~s}$ and viewed using the FEI Tecnai 12 (FEI, Hillsboro, OR, USA). Digital images were recorded on a Tietz TemCamF214 camera (TVIPS, Gauting, Germany).

\section{Recovery of Tracer Viruses}

Adenovirus 7. To evaluate the recovery of known viruses using the methodology presented here, plasma samples from healthy human donors were spiked with $10^{7}$ adenovirus 7 particles per milliliter. The number of added viral particles was determined by direct epifluorescence counts of viruses (data not shown). The spiked

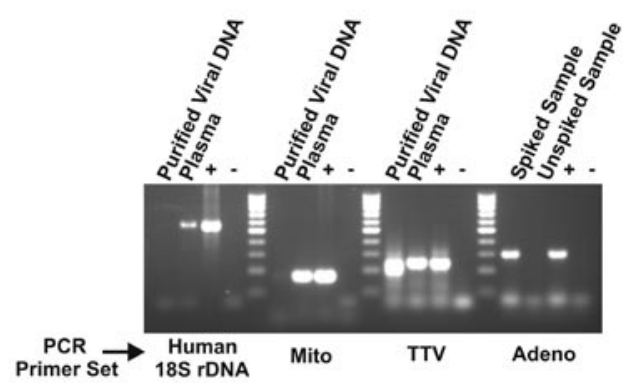

Figure 2. Control PCR assays to determine the quality of the purified viral DNA. A DNA sample was considered a good candidate for library construction if it was negative in the PCR for human 18S rDNA and mitochondria, and positive in the PCR for TTV. Purified viral DNA, viral DNA isolated from healthy donor plasma using the method presented in Protocol 1; plasma, total DNA isolated from healthy donor plasma before any processing; +, DNA extracted from whole blood (18S and mitochondria reactions), DNA from a healthy donor plasma sample known to be positive for TTV, and DNA isolated from the glycerol stock of adenovirus 7 , respectively; -, no target DNA added to PCR; spiked sample, purified viral DNA isolated from a plasma sample spiked with $10^{7}$ adenovirus 7 particles per milliliter; unspiked sample, purified viral DNA isolated from the same plasma sample processed in parallel, but not spiked. TTV, Torque teno virus. samples were processed as outlined in Protocol 1. The presence of adenovirus 7 was determined in both spiked and unspiked samples based on PCR for the hexon gene as previously described by Echavarria et al. (25). The PCR conditions for the detection of the adenovirus 7 sequence were identical to those described above. Adenovirus 7 was not used as a tracer in any of the samples used for constructing the shotgun libraries.

Bacteriophage M13. In order to determine the ability of this method to recover ssDNA viruses, the pooled plasma used to construct Libraries 1 and 2 were spiked with $10^{7}$ particles of bacteriophage M13 (22) per milliliter before processing the samples as outlined in Protocol 1. The presence of spiked M13 in the purified viral samples was not monitored by PCR, but was determined based on TBLASTX similarities of the shotgun library sequences.

\section{Construction of Viral Shotgun \\ Libraries}

Linker-amplified shotgun libraries-Libraries 1 and 2. Once viral DNA samples were determined to be free of mitochondrial and host DNA, linker-amplified shotgun libraries (LASLs) were constructed by Lucigen (Middleton, WI, USA) using a modification of the protocol described by Breitbart et al. (www. sci.sdsu.edu/PHAGE/LASL) (26). Total DNA was initially amplified using the strand-displacement enzyme Bst DNA polymerase (New England BioLabs, Beverly, MA, USA). The amplified DNA was then sheared into $1-2 \mathrm{~kb}$ fragments using a HydroShear ${ }^{\circledR}$ (GenMachines, San Carlos, CA, USA), the fragments were endrepaired, and short double-stranded DNA (dsDNA) linkers were ligated to the ends. These fragments were then PCR-amplified using primers to the linkers and cloned into the pSMART vector as previously described (26). Transformants were sequenced by SymBio (Menlo Park, CA, USA) using the AmpL2 primer. Sequences have been submitted to
GenBank $^{\circledR}$ with the accession nos. DQ092578-DQ092599.

GenomiPhi and whole genome amplification-Library 3. For Library 3, an alternative method for constructing shotgun libraries was tested on the same sample that was used to make Library 2. The DNA was first amplified using the stranddisplacement $\varphi 29$ DNA polymerase (GenomiPhi ${ }^{\mathrm{TM}}$; Amersham Biosciences, Piscataway, NJ, USA) according to the manufacturer's protocol. The products of the GenomiPhi reaction were then fragmented and further amplified using the GenomePlex ${ }^{\circledR}$ Whole Genome Amplification Kit (Sigma-Aldrich). The resulting OmniPlex library was put through a PCR clean-up kit (Mo Bio Laboratories, Solana Beach, CA, USA) and cloned using pGEM $^{\circledR}$ (Promega, Madison, WI, USA). Transformants were sequenced by the San Diego State University Microchemical Core Facility (San Diego, CA, USA) using the M13F primer.

\section{Bioinformatic Analysis of Shotgun Library Sequences}

Quality scores were assigned to the sequences using Phred $(27,28)$, and the sequences were trimmed using SequencherTM 4.0 (Gene Codes, Ann Arbor, MI, USA). Sequences were trimmed until there were not more than 3 bases with confidence scores below 25 within 25 bases of either end. Sequences were compared against GenBank using TBLASTX $(29,30)$. For phylogenetic analyses of the novel anellovirus sequences (SDSU1 and SDSU2), sequences showing significant TBLASTX hits were downloaded from GenBank. The sequences were then aligned using CLUSTALX (31) and neighbor-joining trees were constructed, bootstrapped 1000 times, and analyzed using Treeview (see Figure 3) (32).

\section{PCR for Specific Sequences Identified by Shotgun Library Sequencing}

Primer 3 (33) was used to design primers to amplify three of the viral sequences identified through sequencing of the shotgun libraries. 
The primers were designed to amplify sequences that had top TBLASTX hits to an uncultured anellovirus (DQ092578), SENV (DQ092579), and TLMV (DQ092580).

The PCR mixture $(50 \mu \mathrm{L}$ total volume) for the specific primer sets contained $5 \mu \mathrm{L}$ of target DNA, 1× FideliTaq PCR Master Mix, and $1 \mu \mathrm{M}$ each primer. The thermal cycler conditions were $5 \mathrm{~min}$ at $94^{\circ} \mathrm{C} ; 35$ cycles of $1 \mathrm{~min}$ at $94^{\circ} \mathrm{C}, 1 \mathrm{~min}$ at $60^{\circ}-0.5^{\circ} \mathrm{C}$ per cycle, $1 \mathrm{~min}$ at $72^{\circ} \mathrm{C}$; and $10 \mathrm{~min}$ at $72^{\circ} \mathrm{C}$. The identity of PCR positives was confirmed by sequencing.

\section{RESULTS}

\section{Electron Microscopy of Purified Blood Viruses}

Electron microscopy (Figure 1) verified the presence of viral particles in the plasma of healthy blood donors. The majority of the viral particles observed were approximately 100 $\mathrm{nm}$ in diameter. In all cases, the viral particles were concentrated in the band isolated from the $\mathrm{CsCl}$ gradient, and no viruses were observed in the other fractions after centrifugation (data not shown).

\section{Removal of Human and Mitochondrial DNA}

Because high host and mitochondrial DNA concentrations overwhelmed the viral DNA signal (data not shown), $\mathrm{CsCl}$ density-dependent centrifugation, chloroform, and DNase I treatments were used to remove human and mitochondrial DNA. Free human DNA was removed beyond the detection limit of the PCR assay by the $\mathrm{CsCl}$ centrifugation and DNase I treatment (Figure 2 ). The addition of chloroform was necessary to disrupt the mitochondrial membranes, making them susceptible to DNase I digestion. Viral nucleic acids were protected from DNase I degradation by the viral protein capsids, although some enveloped viruses may have been lost. PCR assays showed that this method significantly reduced the concentrations of host and mitochondrial DNA compared with whole plasma, without resulting in observable losses of viral DNA (Figure 2 and data not shown).

\section{Recovery of Viral DNA}

PCR-based control experiments showed that both naturally present TTV and artificially spiked adenovirus 7 tracers were recovered from human plasma using this method (Figure 2). Because concentrations of adenovirus can reach up to $10^{10}$ viruses per milliliter in the blood of infected patients (34), an addition of $10^{7}$ viruses per milliliter is physiologically relevant.
TBLASTX analysis of the sequences from the viral shotgun libraries showed that this method recovered artificially spiked bacteriophage M13 as well as naturally present anelloviruses. For the libraries that were artificially spiked with $10^{7}$ bacteriophage M13 particles per milliliter, $20 \%-40 \%$ of the shotgun library sequences originated from bacteriophage M13 (as determined by TBLASTX similarity). These sequences could be assembled into larger contigs, demonstrating that the genome of a virus present at a concentration of $10^{7}$ virions
A

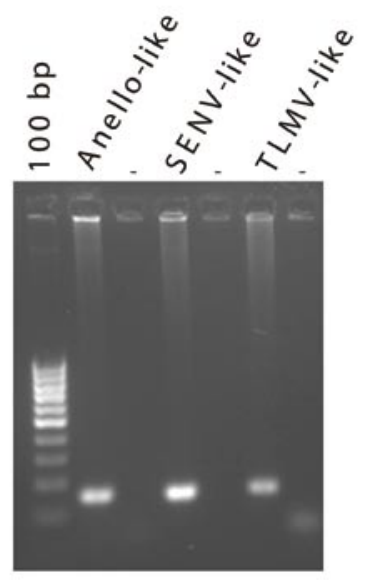

C

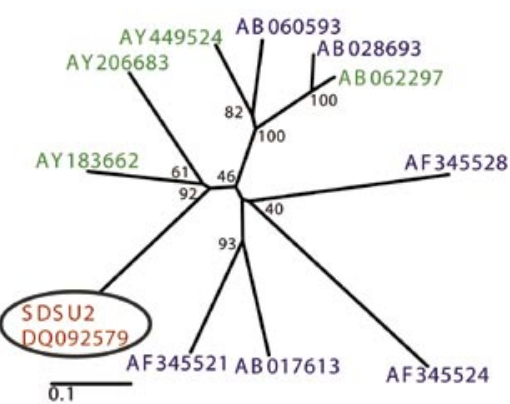

DNA

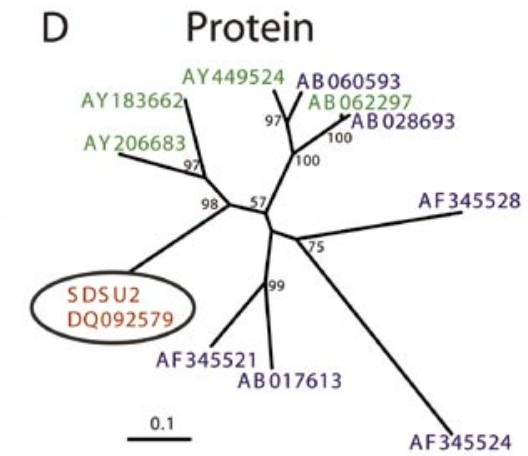

B Protein

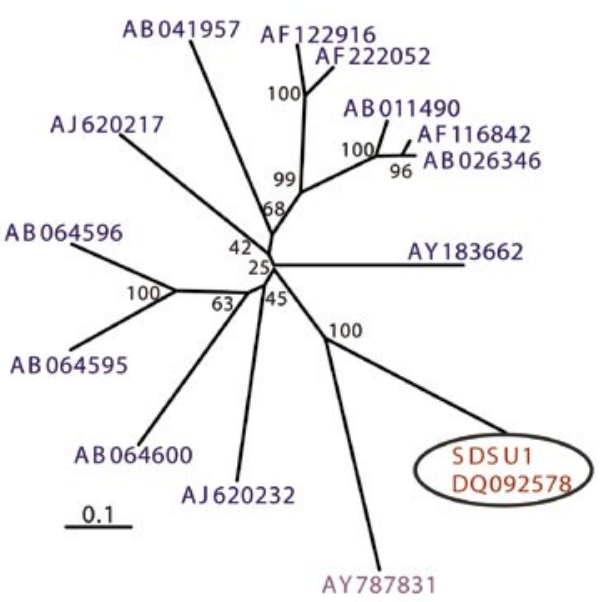

\section{SENV \\ TTV \\ Small anellovirus 2}

Figure 3. Novel anellovirus sequences identified in the plasma of healthy donors. Sequences having top TBLASTX hits to small anellovirus 2 (DQ092578), SEN virus (DQ092579), and TLMV (DQ092580) were recovered from the shotgun libraries. (A) Specific PCR primers designed to amplify these novel anellovirus sequences verified the presence of these sequences in the plasma of different healthy donors. (B-D) Phylogenetic trees showing the relationships of the anellovirus sequences identified in this study (SDSU1 and SDSU2) to previously sequenced anelloviruses. Sequences identified in this study are shown in red, SENV sequences are green, TTV sequences are blue, and the small anellovirus 2 sequence is light purple. All positive PCR products were sequenced for verification. The scale bar represents 0.1 changes per 100 bp. TTV, Torque teno virus; TLMV, TTV-like mini virus; SENV, SEN virus. 
Table 1. Primer Sequences Utilized in this Study

\begin{tabular}{|c|c|c|c|}
\hline Primer Name & Sequence & Target & Reference \\
\hline $\begin{array}{l}18 S F \\
18 S R\end{array}$ & $\begin{array}{l}\text { 5'-CCGCAGCTAGGAATAATGGAATAGGAC-3' } \\
\text { 5'-GTTAGCATGCCAGAGTCTCGTTCGT-3' }\end{array}$ & $\begin{array}{l}\text { Human } 18 S \\
\text { rDNA }\end{array}$ & $\begin{array}{l}\text { Maxim Biotech } \\
\text { (San Francisco, } \\
\text { CA, USA) }\end{array}$ \\
\hline $\begin{array}{l}\text { Mit3130F } \\
\text { Mit3301R }\end{array}$ & $\begin{array}{l}\text { 5'-AGGACAAGAGAAATAAGGCC-3' } \\
\text { 5'-TAAGAAGAGGAATTGAACCTCTGACTGTAA-3' }\end{array}$ & $\begin{array}{l}\text { Human } \\
\text { mitochondria }\end{array}$ & (35) \\
\hline $\begin{array}{l}\text { TTVBF1 } \\
\text { TTVBR1 } \\
\text { TTVCF1 } \\
\text { TTVCR1 }\end{array}$ & $\begin{array}{l}\text { 5'-GTGGGACTTTCACTTGTCGGTGTC-3' } \\
\text { 5'-GACAAATGGCAAGAAGATAAAGGCC-3' } \\
\text { 5'-CAGACTCCGAGTTGCCATTGGAC-3' } \\
\text { 5'-CACGTGTCGGGGCCTACTTCCG-3' }\end{array}$ & $\begin{array}{l}\text { TTV } \\
\text { (outer PCR) }\end{array}$ & (41) \\
\hline $\begin{array}{l}\text { TTVBF2 } \\
\text { TTVBR2 } \\
\text { TTVCF2 } \\
\text { TTVCR2 }\end{array}$ & $\begin{array}{l}\text { 5'-AGGTCACTAAGCACTCCGAGCG-3' } \\
\text { 5'-GCGAAGTCTGGCCCCACTCAC-3' } \\
\text { 5'-GCAACGAAAGTGAGTGGGGCCAG-3' } \\
\text { 5'-GGTTTCCGCCGAGGATGACCT-3' }\end{array}$ & $\begin{array}{l}\text { TTV } \\
\text { (inner PCR) }\end{array}$ & (41) \\
\hline $\begin{array}{l}\text { hexAA1885F } \\
\text { hexAA1913R }\end{array}$ & $\begin{array}{l}\text { 5'-GCCGCAGTGGTCTTACATGCACATC-3' } \\
\text { 5'-CAGCACGCCGCGGATGTCAAAGT-3'3' }\end{array}$ & $\begin{array}{l}\text { Adenovi- } \\
\text { rus } 7\end{array}$ & (25) \\
\hline $\begin{array}{l}\text { AnelloF } \\
\text { AnelloR }\end{array}$ & $\begin{array}{l}\text { 5'-GCACATTCTTTTAAGAGCTGTTTTTT-3' } \\
\text { 5'-AGCAGACCCAGGACAACAAG-3' }\end{array}$ & $\begin{array}{l}\text { Novel anel- } \\
\text { lovirus }\end{array}$ & This study \\
\hline $\begin{array}{l}\text { SENF } \\
\text { SENR }\end{array}$ & $\begin{array}{l}\text { 5'-AAGGCAAAGGAAACATGGTG-3' } \\
\text { 5'-TGTGAAGGGGCCTAGTGTTC-3' }\end{array}$ & Novel SENV & This study \\
\hline $\begin{array}{l}\text { TLMVF } \\
\text { TLMVR }\end{array}$ & $\begin{array}{l}\text { 5'-CGAACCATATCCAACAGAACAA-3' } \\
\text { 5'-GTGGTAATGATGGCATGCTG-3' }\end{array}$ & Novel TLMV & This study \\
\hline
\end{tabular}

viruses in this protocol through the removal of blood cells by centrifugation, the purification of viruses by $\mathrm{CsCl}$ densitydependent centrifugation, chloroform addition to lyse mitochondria, and DNase I treatment to remove nonviral DNA. This selection eliminates the need for the background human DNA signal subtraction that is performed in RDA analysis (8). It is important to note that the method outlined here employs a $\mathrm{CsCl}$ gradient for purifying viruses instead of filtration-based techniques. Filtering samples through a $0.2-\mu \mathrm{m}$ filter $(12,13)$ to remove cells and mitochondria may result in the loss of large viral particles (e.g., some herpesviruses are $0.2 \mu \mathrm{m}$ in diameter) (22).

A 284-bp sequence recovered from Library 3 (SDSU2; DQ092579) was $67 \%$ identical on the nucleotide level and $63 \%$ identical on the amino acid level to SENV (AY206683) (Figure 3, $\mathrm{C}$ and $\mathrm{D}$ ). These divergent anellovirus sequences constitute novel viruses identified using the methods presented here and contribute to the wide genomic heterogeneity of this group.

\section{Specific PCR to Confirm the Presence of Novel Anelloviruses}

PCR primers designed to amplify three of the novel anellovirus sequences identified in this study confirmed their presence in blood pooled from 100 different healthy donors (Figure 3A). PCR positives were sequenced for confirmation, and all amplified sequences were identical to those initially recovered from the shotgun libraries.

\section{DISCUSSION}

The method described here provides a new technique for sequencing novel DNA viruses from plasma samples. There is a high level of selection for

\section{Depletion of Human and Mitochondrial DNA}

Removal of free human host DNA was a critical step in this method because free human DNA may be present at significantly higher concentrations than viral DNA in plasma. Free human DNA was removed beyond the detection limit of our PCR conditions for human $18 \mathrm{~S}$ rDNA by the $\mathrm{CsCl}$ density-dependent centrifugation and DNase I treatment (Figure 2).

In addition to removing free DNA, it was also necessary to remove mitochondria from the plasma sample. Chiu et al. (35) have shown that mitochondrial DNA is present in human plasma in both particle-associated and free forms. Preliminary experiments showed that if the mitochondria were not specifically removed from the plasma sample (by chloroform and then DNase I treatment), all the sequences recovered from the shotgun libraries were mitochondrial in origin (data not shown). The depletion protocols described here efficiently reduced the concentrations of mitochondrial DNA 
Table 2. Sequences from the Healthy Blood Donor Shotgun Libraries with Significant TBLASTX Similarities to Known Viruses

\begin{tabular}{|c|c|c|}
\hline $\begin{array}{l}\text { Library } \\
\text { (No.) }\end{array}$ & Top Known Virus Hit & TBLASTX E-value \\
\hline 1 & TTV-like mini virus & $9 e-04$ \\
\hline 1 & TTV-like mini virus & $3 e-25$ \\
\hline 2 & TTV-like mini virus & $2 e-15$ \\
\hline 1 & Heliothis zea virus 1 & $1 e-15$ \\
\hline 1 & Heliothis zea virus 1 & $2 e-16$ \\
\hline 1 & Heliothis zea virus 1 & $9 e-17$ \\
\hline 1 & Heliothis zea virus 1 & $4 e-11$ \\
\hline 1 & Pseudorabies virus & $7 e-05$ \\
\hline 1 & Bacteriophage $\varphi 3626$ & $2 e-27$ \\
\hline 1 & Cowpox virus & $1 e-19$ \\
\hline 1 & Cowpox virus & $1 e-19$ \\
\hline 1 & Human endogenous retrovirus $\mathrm{H}(\mathrm{HERV}-\mathrm{H})$ & $1 e-25$ \\
\hline 1 & Human endogenous retrovirus $\mathrm{H}$ (HERV-H) & $5 e-25$ \\
\hline 1 & Bacteriophage EJ-1 & $2 e-05$ \\
\hline 1 & Human herpesvirus 3 & $5 e-05$ \\
\hline 1 & TTV & $2 e-24$ \\
\hline 1 & TTV & $1 e-04$ \\
\hline 2 & Small anellovirus $2^{a}$ & $3 e-06$ \\
\hline 1 & Methanobacterium phage psiM2 & $1 e-04$ \\
\hline 1 & Spodoptera litura nucleopolyhedrovirus & $7 e-08$ \\
\hline 1 & Chlamydia phage $\varphi$ CPAR39 & $1 e-09$ \\
\hline 3 & SEN virus ${ }^{a}$ & $8 e-38$ \\
\hline \multicolumn{3}{|c|}{$\begin{array}{l}\text { TTV, Torque teno virus. } \\
\text { aSequences that were further analyzed to identify phylogenetic relationships to known viruses } \\
\text { (Figure } 3, B-D \text { ). }\end{array}$} \\
\hline
\end{tabular}

to the point that we could no longer detect mitochondrial DNA by PCR (Figure 2), and only a few sequences with TBLASTX similarities to mitochondria were recovered from the shotgun libraries.

\section{Identification of Novel Anellovirus Sequences}

Among the shotgun sequences obtained from healthy donor plasma, several sequences with similarities to the anellovirus family were identified (Table 2). The anellovirus family (formerly part of the circovirus family) is a highly heterogeneous group of single-stranded, circular viruses, including TTV, TLMV, and SENV. Using the methodology presented here, we have detected several novel anellovirus sequences, which suggests that there is still undiscovered diversity within this family of viruses. Anelloviruses are present worldwide and are found in over $70 \%$ of the general population of Asia, Africa, and South America (17). These viruses appear to be less prevalent in the U.S. and Europe (16); however, TTV viremia occurs in $8 \%-42 \%$ of healthy blood donors in the U.S. $(36,37)$ and $47 \%-73 \%$ of individuals in European countries (17). It has been suggested that TTV and SENV are associated with posttransfusion hepatitis; however, no definitive links between the presence of these viruses and clinical pathology have been demonstrated.

\section{Possible Loss of Enveloped Viruses}

The chloroform treatment that is required for lysing mitochondria will also disrupt the membrane of enveloped viruses. In control experiments with the enveloped virus HSV-1, the protein capsid remained intact and protected the viral DNA from degradation even after removal of the envelope (data not shown). Therefore, at least some enveloped viruses can be recovered using this method. However, the capsid of some viruses may not be stable after the removal of the envelope, and if these viruses were rendered DNase-sensitive, then they would not be recovered using this approach. One possible alternative to the chloroform treatment is antibodybased depletion of the mitochondria. However, we found that this method did not consistently reduce mitochondrial numbers and had variable effects on the efficiency of viral recovery (data not shown).

\section{Blood Sample Collection and Storage}

This method was tested on blood samples that were collected using heparin as the anticoagulant and stored at either room temperature or $4^{\circ} \mathrm{C}$. One needs to take caution when using blood preserved in EDTA, acid citrate dextrose, sodium citrate, and potassium or ammonium oxalate because these compounds chelate cations that are required for effective DNase I digestion and may compromise the integrity of viral particles. Further studies need to be performed to determine the ability of this method to recover viruses from frozen samples, serum, or blood fraction paste.

\section{Applications of this Protocol}

Here we have shown that a method based on the selection for viral particles followed by sequence-independent amplification can recover DNA viral sequences from the blood of healthy people. Applying this technique to large donor pools will allow for the identification of viruses normally present in the blood supply. This will provide a baseline against which samples can be compared in order to identify emerging threats even before clinical symptoms are observed. In addition to its use for monitoring the blood supply, this method can also be applied to diagnose unknown viral infections in patients. For example, more than 50\% of pneumonia cases and almost $60 \%$ of encephalitis cases requiring hospitalization in the U.S. have no known etiology $(38,39)$. In the case of many viral infections, viremia phases are characterized by high viral titers, which would facilitate the sequencing of the viruses using this method. Knowledge 
about the identity of these viruses may yield insights into treatment options.

Because many viruses are cellassociated (e.g., Epstein-Barr virus and cytomegalovirus), one logical step for further development of this method is its application to human tissues. The method outlined here can also easily be adapted to identify RNA viruses through the addition of a reverse transcription step before the sequence-independent amplification $(12,13)$. Finally, this method can also be applied to detect novel DNA viruses within animal populations, which is of potential importance for both farming and human health.

The protocol described here can be completed (sample collection to sequence data) in fewer than 2 days, which is faster than traditional protocols that require obtaining the virus in culture. Once sequence data are obtained from the newly identified virus of interest, PCR primers can be designed to rapidly screen a large number of samples in order to determine the prevalence, abundance, and geographical distribution of the novel virus. The safety of the blood supply can be monitored, and viral sequences can be compared in order to determine the origin of the virus and epidemiological links between patients (40).

\section{ACKNOWLEDGMENTS}

The authors thank Leigh Anderson and Norman Anderson for the enlightening conversations that led to the initiation of this project and all their help along the way. Thanks to Millie Dizon, Terry Frey, Deron Herr, Stanley Maloy, Kathie McGuire, Leo Su, Constantine Tsoukas, Jason Wall, and Linda Wegley for helpful discussions and sampling guidance. We also thank SymBio and the SDSU Microchemical Core Facility for sequencing, and Steve Barlow at the SDSU Microscopy Facility for help with the electron microscopy. The electron microscope was supported by NSF instrumentation grant no. DBI-0308029. Thanks to Kendis Cox and Priscilla Crisler at the General Clinical Research Center at The Scripps Research Institute, Dave
Hammond, Julia Lathrop, and Grigori Prikhodko at the American Red Cross, and Sue Johnston at the SDSU Health Center for providing samples. David Mead developed the modified LASL technology utilized in this method, and Rob Edwards was instrumental in the bioinformatic analyses. The adenovirus 7 and bacteriophage M13 used for controls were kindly provided by Norman Anderson at the Viral Defense Foundation and Ralph Faust at Georgetown University. This work was supported by NSF DEB-BE 04-21955 to F.R. M.B. was supported by an EPA STAR fellowship.

\section{COMPETING INTERESTS STATEMENT}

The authors declare no competing interests.

\section{REFERENCES}

1.Nathanson, N. 1998. Emergence of new viral infections: implications for the blood supply. Biologicals 26:77-84

2. Farrugia, A. 2004. The mantra of blood safety: time for a new tune? Vox Sang. 86:1-7.

3. Wu, Y. and E. Snyder. 2003. Safety of the blood supply: role of pathogen reduction. Blood Rev. 17:111-122.

4.Goodnough, L., A. Shander, and M. Brecher. 2003. Transfusion medicine: looking to the future. Lancet 361:161-169.

5. Wang, D., A. Urisman, Y.T. Liu, M. Springer, T.G. Ksiazek, D.D. Erdman, E.R. Mardis, M. Hickenbotham, et al. 2003. Viral discovery and sequence recovery using DNA microarrays. PLoS Biol. 1:257-260.

6. Drosten, C., S. Gunther, W. Preiser, S. van der Werf, H.-R. Brodt, S. Becker, H. Rabenau, M. Panning, et al. 2003. Identification of a novel coronavirus in patients with severe acute respiratory syndrome. N. Engl. J. Med. 348:1967-1976.

7. Lisitsyn, N., N. Lisitsyn, and M. Wigler. 1993. Cloning the differences between two complex genomes. Science 259:946-951.

8. Choo, Q., G. Kuo, A. Weiner, L. Overby, D. Bradley, and M. Houghton. 1989. Isolation of a cDNA clone derived from a blood-borne non-A, non-B viral hepatitis genome. Science 244:359-362.

9.Simons, J., T. Pilot-Matias, T. Leary, G. Dawson, S. Desai, G. Schlauder, A. Muerhoff, J. Erker, et al. 1995. Identification of two flavivirus-like genomes in the GB hepatitis agent. Proc. Natl. Acad. Sci. USA 92:3401-3405.

10.Chang, Y., E. Cesarman, M. Pessin, F. Lee, J. Culpepper, D. Knowles, and P. Moore. 1994. Identification of herpesvirus-like DNA sequences in AIDS-associated Kaposi's sarcoma. Science 266:1865-1869.

11.Nishizawa, T., H. Okamoto, K. Konishi, H. Yoshizawa, Y. Miyakawa, and M. Mayumi. 1997. A novel DNA virus (TTV) associated with elevated transaminase levels in posttransfusion hepatitis of unknown etiology. Biochem. Biophys. Res. Commun. 241:9297.

12.Allander, T., S. Emerson, R. Engle, R. Purcell, and J. Bukh. 2001. A virus discovery method incorporating DNase treatment and its application to the identification of two bovine parvovirus species. Proc. Natl. Acad. Sci. USA 98:11609-11614.

13.Stang, A., K. Korn, O. Wildner, and K. Uberla. 2005. Characterization of virus isolates by particle-associated nucleic acid PCR J. Clin. Microbiol. 43:716-720.

14.Jones, M.S., A. Kapoor, V.V. Lukashov, P. Simmonds, F. Hecht, and E. Delwart. 2005. New DNA viruses identified in patients with acute viral infection syndrome. J. Virol. 79:8230-8236.

15.Hino, S. 2002. TTV, a new human virus with single stranded circular DNA genome. Rev. Med. Virol. 12:151-158.

16.Yzebe, D., S. Xueref, D. Baratin, A. Bouletreau, J. Fabry, and P. Vanhems. 2002. TT virus: a review of the literature. Panminerva Med. 44:167-177.

17.Bendinelli, M., M. Pistello, F. Maggi, C. Fornai, G. Freer, and M. Vatteroni. 2001 Molecular properties, biology, and clinical implications of TT virus, a recently identified widespread infectious agent of humans. Clin. Microbiol. Rev. 14:98-113

18.Takahashi, K., Y. Iwasa, M. Hijikata, and S. Mishiro. 2000. Identification of a new DNA virus (TTV-like mini virus, TLMV) intermediately related to TT virus and chicken anemia virus. Arch. Virol. 145:979-993.

19.Sagir, A., O. Kirschberg, T. Heintges, A. Erhardt, and D. Haussinger. 2004. SEN virus infection. Rev. Med. Virol. 14:141-148.

20. Young, L. and A. Rickinson. 2004. EpsteinBarr virus: 40 years on. Nat. Rev. Cancer 4:757-768.

21.Corcoran, A. and S. Doyle. 2004. Advances in the biology, diagnosis and host-pathogen interactions of parvovirus B19. J. Med Microbiol. 53:459-475.

22.Murphy, F.A., C.M. Fauquet, D.H.L. Bishop, S.A. Ghabrial, A.W. Jarvis, G.P. Martelli, M.A. Mayo, and M.D. Summers (Eds.). 1995. Virus Taxonomy: Sixth Report of the International Committee on Taxonomy of Viruses. Springer-Verlag, New York.

23.Noble, R.T. and J.A. Fuhrman. 1998. Use of SYBR Green I for rapid epifluorescence counts of marine viruses and bacteria. Aquat. Microb. Ecol. 14:113-118.

24.Hazelton, P. and H. Gelderblom. 2003. Electron microscopy for rapid diagnosis of infectious agents in emergent situations. Emerg. Infect. Dis. 9:294-303.

25.Echavarria, M., M. Forman, J. Ticehurst, J. Dumler, and P. Charache. 1998. PCR method for detection of adenovirus in urine of healthy and human immunodeficiency virus-infected individuals. J. Clin. Microbiol. 36:3323-3326. 
26.Breitbart, M., P. Salamon, B. Andresen, J.M. Mahaffy, A.M. Segall, D. Mead, F. Azam, and F. Rohwer. 2002. Genomic analysis of uncultured marine viral communities. Proc. Natl. Acad. Sci. USA 99:14250-14255.

27.Ewing, B. and P. Green. 1998. Base-calling of automated sequencer traces using phred. II. Error probabilities. Genome Res. 8:186-194.

28.Ewing, B., L. Hillier, M. Wendl, and $P$. Green. 1998. Basecalling of automated sequencer traces using phred. I. Accuracy assessment. Genome Res. 8:175-185.

29.Altschul, S.F., W. Gish, W. Miller, E.W. Myers, and D.J. Lipman. 1990. Basic local alignment search tool. J. Mol. Biol. 215:403410

30.Altschul, S.F., T.L. Madden, A.A. Schäffer, J. Zhang, Z. Zhang, W. Miller, and D.J. Lipman. 1997. Gapped BLAST and PSIBLAST: a new generation of protein database search programs. Nucleic Acids Res. 25:33893402 .

31.Thompson, J.D., T.J. Gibson, F. Plewniak, F. Jeanmougin, and D.G. Higgins. 1997. The Clustal $\mathrm{X}$ windows interface: flexible strategies for multiple sequence alignment aided by quality analysis tools. Nucleic Acids Res. 24:4876-4882.

32.Page, R. 1996. TREEVIEW: an application to display phylogenetic trees on personal computers. Comput. Appl. Biosci. 12:357-358.

33.Rozen, S. and H. Skaletsky. 2000. Primer3 on the WWW for general users and for biologist programmers, p. 365-386. In S. Krawetz and S. Misener (Eds.), Bioinformatics Methods and Protocols: Methods in Molecular Biology. Humana Press, Totowa, NJ.

34.Heim, A., C. Ebnet, G. Harste, and P. Pring-Akerblom. 2003. Rapid and quantitative detection of human adenovirus DNA by real-time PCR. J. Med. Virol. 70:228-239.

35.Chiu, R., L. Chan, N. Lam, N. Tsui, E. Ng, T. Rainer, and Y. Lo. 2003. Quantitative analysis of circulating mitochondrial DNA in plasma. Clin. Chem. 49:719-726.

36.Handa, A., B. Dickstein, N.S. Young, and K.E. Brown. 2000. Prevalence of the newly described human circovirus, TTV, in United States blood donors. Transfusion 40:245-251.

37.Leary, T., J. Erker, M. Chalmers, S. Desai, and I. Mushahwar. 1999. Improved detection systems for TT virus reveal high prevalence in humans, non-human primates and farm animals. J. Gen. Virol. 80:2115-2120.

38. Khetsuriani, N., R. Homan, and $L$. Anderson. 2002. Burden of encephalitis-associated hospitalizations in the United States, 1988-1997. Clin. Infect. Dis. 35:175-182.

39.Ruiz, M., S. Ewig, M. Marcos, J. Martinez, F. Arancibia, J. Mensa, and A. Torres. 1999. Etiology of community-acquired pneumonia: Impact of age, comorbidity, and severity. Am. J. Respir. Crit. Care Med. 160:397-405.

40.Liu, J., S.L. Lim, Y. Ruan, A.E. Ling, L.F. Ng, C. Drosten, E.T. Liu, L.W. Stanton, and M.L. Hibberd. 2005. SARS transmission pattern in Singapore reassessed by viral sequence variation analysis. PLoS Med. 2:162-168.

41.Leary, T.P., J.C. Erker, M.L. Chalmers, S.M. Desai, and I.K. Mushahwar. 1999. Optimized PCR assay for the detection of TT virus. J. Virol. Methods 82:109-112.
Received 30 April 2005; accepted 1 July 2005

\section{Address correspondence to:}

Mya Breitbart

San Diego State University

5500 Campanile Drive, LS301

San Diego, CA 92182-4614, USA

e-mail: mya@sunstroke.sdsu.edu

To purchase reprints

of this article, contact

Reprints@BioTechniques.com 